\section{Duration of the efficacy of omalizumab after treatment discontinuation in 'real life' severe asthma}

\section{ABSTRACT}

Efficacy of omalizumab in severe asthma is well documented; however, the optimal duration of the treatment remains unclear. In an open prospective study, we sought to assess the persistence of response in subjects withdrawing from omalizumab treatment. We evaluated 49 patients who voluntarily accepted to discontinue omalizumab treatment after 6 years of therapy. Asthma relapse was defined as any severe asthma exacerbation associated with loss of asthma control. Twelve patients relapsed in the first year of followup, and 7 within 13 and 48 months. These results suggest that the effects of 6 years of omalizumab may persist after discontinuation of therapy in $60 \%$ of patients for at least 4 years.

Omalizumab is a humanised monoclonal anti-IgE used to treat severe allergic asthma. Although the clinical efficacy of omalizumab in severe asthma has been well documented, there is as yet limited information on the consequences of discontinuing the therapy after a prolonged period of positive response to treatment. ${ }^{1}$ Pharmacokinetic/dynamic modelling has predicted that IgE production decreases throughout treatment, reaching a new equilibrium after approximately 5 years. It has been hypothesised that IgE production would increase very slowly after discontinuation, returning to baseline after 15 years, meaning patients would not need omalizumab indefinitely. ${ }^{2}$

A recent randomised, double-blind, placebo-controlled study evaluated the persistency of clinical response in patients continuing or withdrawing from omalizumab therapy after $\geq 5$ years of treatment. ${ }^{3}$ Continuation of treatment resulted in better maintenance of asthma control and lower exacerbation risk in the 1-year follow-up. ${ }^{3}$ However, there are no data on the progression of asthma after discontinuation of omalizumab beyond 1 year. Such studies can hardly be performed in the form of double-blind, placebo-controlled trials. It is therefore necessary to study this question through real-life studies.

The objective of this open prospective study was to assess the persistence of response in subjects withdrawing from long-term omalizumab treatment. Participants were recruited from the Spanish
Omalizumab Registry, ${ }^{4}$ responders to omalizumab treatment. There were 51 eligible patients, and 49 of them voluntarily agree to discontinue the treatment after 6 years of therapy. In case of failure, the patient could choose to either reinitiate omalizumab or be included in another biological therapy. All patients provided written informed consent for their participation in the study. The tests used in the statistical analysis are available in the online supplementary appendix.

The mean time of treatment was $5.8 \pm 0.8$ (SD) years. The mean age was $55.7 \pm 11.2$ years, and 35 were women (71.4\%). Efficacy of omalizumab after visit of cessation (VC) was evaluated at 6 (V6) and 12 months (V12). Asthma exacerbations rate (ER), Asthma Control Test (ACT) ${ }^{5}$ and Global Evaluation of Therapeutic Efficacy (GETE) ${ }^{6}$ were used to assess the level of control of the disease. The absolute serum eosinophil (ASE) numbers and $\mathrm{FEV}_{1}$ (\% of predicted) were also evaluated. Patients with loss of asthma control due to one or more severe asthma exacerbations, requiring systemic corticosteroids associated with clinical deterioration detected by changes in GETE and ACT at some point in their follow-up, were considered 'failure of suspension' (failure group). Patients without asthma exacerbations or with only one isolated exacerbation occurring in an otherwise well-controlled asthma were considered 'success of suspension' (success group).

Of the 49 patients, $37 \quad(75.5 \%)$ showed 'success of suspension' while 12 $(24.5 \%)$ were failures in the first year of follow-up. In seven patients the relapse occurred within the first 6 months after omalizumab discontinuation, while in five patients asthma deterioration took place within 6 and 12 months. Ten of them restarted treatment with omalizumab with good response and two were included in clinical trials with other monoclonal antibodies.

The following demographic and clinical characteristics: atopy (prick test), chronic rhinosinusitis (CRS), nasal polyps (chronic rhinosinustis with nasal polyps (CRwNP)), non-steroidal anti-inflammatory drugs (NSAIDs) intolerance, ACT, ER and $\mathrm{FEV}_{1}(\%)$ before initiating omalizumab treatment were similar in the success and failure groups. There were more patients with CRS, nasal polyps and NSAIDs intolerance in the failure group than in the success group, but the difference was not statistically significant $(p=0.09)$ (see online supplementary table E1). There were no differences in ER and asthma treatment between failure and success groups either before the initiation of omalizumab or in the year prior to discontinuation (see online supplementary tables E2-E4).

Differences between groups were evaluated only at V6 because patients who relapsed either reinitiated omalizumab or were included in clinical trials with other biodrugs, and thus could no longer be assessed. Despite clinical deterioration, no significant changes in $\mathrm{FEV}_{1}$ were observed at V6 in the failure group. The ASE value only increased in the failure group at V6 with respect to VC (table 1).

As the result of the formation of omalizumab/IgE complexes, 6 years of omalizumab therapy was associated with a statistically significant increase in total $\mathrm{IgE}$ values with respect to those found before omalizumab was initiated (table 1). The increase in total $\mathrm{IgE}$ was much higher in the failure group (median increase $+420.0 \mathrm{IU} /$ $\mathrm{mL}$ ) than in the success group (median increase $+80.5 \mathrm{IU} / \mathrm{mL}) \quad(\mathrm{p}=0.02)$. When omalizumab was withdrawn, a significant decrease in IgE between VC and V6 was observed. The decrease was greater in the failure group (median decrease of -269.0 $\mathrm{IU} / \mathrm{mL}$ ) than in the success group (median decrease of $-145.5 \mathrm{IU} / \mathrm{mL}$ ). The difference in the changes between the two groups was near statistical significance $(p=0.054)$ (table 1). These results might suggest that the faster IgE decreases, the earlier asthma relapses.

In our study, $75.5 \%$ of patients maintained control of asthma at V12. Most failure cases took place within the first 6 months. In the XPORT study, 67.7\% of patients in the treatment group maintained control of asthma at V12. However, an important percentage $(47.7 \%)$ of asthmatics in the placebo group remained well controlled. ${ }^{3}$

In the 37 patients in the success group at the end of 1 year of follow-up, the evolution of ACT and GETE showed statistically significant deterioration between VC and V6 (table 1). These observations suggest that, although these patients did not suffer exacerbations requiring oral corticosteroid therapy, a mild clinical deterioration took place after omalizumab was discontinued.

Although no further clinical statistical analyses were carried out after 1 year, all patients continued under medical supervision for at least 4 years. Of the 37 patients who were in the success group at V12, 5 were in the failure group at V24 (24 months), 1 at V36 (36 months) and 1 at V48 (48 months). All patients in the failure group restarted treatment with omalizumab with good response. 
Table 1 Evolution of the main clinical variables according to success or failure of discontinuation of omalizumab treatment

\begin{tabular}{|c|c|c|c|c|c|c|c|c|c|c|}
\hline Variable & Group & Pretreatment (PT) & Cessation (VC) & Visit 6 months (V6) & $\mathrm{PT}^{*}$ & $\mathrm{VC}^{*}$ & V6* & $\begin{array}{l}\text { PTt vs } \\
\text { vC }\end{array}$ & $\begin{array}{l}\text { PTt vs } \\
\text { v6 }\end{array}$ & $\begin{array}{l}\text { vCt vs } \\
\text { v6 }\end{array}$ \\
\hline \multirow[t]{2}{*}{ GETE } & Success & - & $\begin{array}{l}3.6 \pm 0.5 \\
4.0(3.0-4.0)\end{array}$ & $\begin{array}{l}3.1 \pm 0.9 \\
3.0(3.0-4.0)\end{array}$ & - & n.s. & 0.0098 & - & - & 0.0002 \\
\hline & Failure & - & $\begin{array}{l}3.3 \pm 0.8 \\
3.5(3.0-4.0)\end{array}$ & $\begin{array}{l}2.0 \pm 1.3 \\
2.0(1.0-3.0)\end{array}$ & - & n.s. & & - & - & 0.0313 \\
\hline \multirow[t]{2}{*}{ ACT } & Success & $\begin{array}{l}15.1 \pm 5.5 \\
15.0(10.0-20.0)\end{array}$ & $\begin{array}{l}22.4 \pm 2.7 \\
23.0(21.0-24.0)\end{array}$ & $\begin{array}{l}20.3 \pm 4.1 \\
21.0(16.0-24.0)\end{array}$ & n.s. & n.s. & 0.0036 & $<0.0001$ & $<0.0001$ & 0.0007 \\
\hline & Failure & $\begin{array}{l}12.4 \pm 5.2 \\
13.0(10.0-15.0)\end{array}$ & $\begin{array}{l}20.4 \pm 3.7 \\
21.5(18.0-23.0)\end{array}$ & $\begin{array}{l}14.5 \pm 5.9 \\
13.0(10.0-20.0)\end{array}$ & n.s. & n.s. & & 0.0029 & n.s. & 0.0234 \\
\hline \multirow[t]{2}{*}{ Exacerbation rate } & Success & $\begin{array}{l}4.4 \pm 3.3 \\
3.0(2.0-6.0)\end{array}$ & $\begin{array}{l}0.0(0.0-0.0) \\
0.0(0.0-0.0)\end{array}$ & $\begin{array}{l}0.4 \pm 0.8 \\
0.0(0.0-1.0)\end{array}$ & n.s. & n.s. & 0.0030 & $<0.0001$ & $<0.0001$ & n.s. \\
\hline & Failure & $\begin{array}{l}4.8 \pm 3.9 \\
3.5(1.5-9.5)\end{array}$ & $\begin{array}{l}0.0 \pm 0.0 \\
0.0(0.0-0.0)\end{array}$ & $\begin{array}{l}1.5 \pm 1.1 \\
2.0(0.0-2.0)\end{array}$ & n.s. & n.s. & & 0.0010 & 0.0195 & 0.0078 \\
\hline \multirow[t]{2}{*}{$\mathrm{FEV}_{1}(\%)$} & Success & $\begin{array}{l}63.6 \pm 20.3 \\
61.8(51.7-70.3)\end{array}$ & $\begin{array}{l}70.4 \pm 15.7 \\
68.6(59.0-79.4)\end{array}$ & $\begin{array}{l}68.1 \pm 14.5 \\
64.6(61.2-72.3)\end{array}$ & n.s. & n.s. & n.s. & 0.0276 & 0.0296 & n.s. \\
\hline & Failure & $\begin{array}{l}68.3 \pm 19.4 \\
70.7(59.6-81.6)\end{array}$ & $\begin{array}{l}76.2 \pm 18.3 \\
80.6(64.2-89.2)\end{array}$ & $\begin{array}{l}67.1 \pm 22.1 \\
71.7(40.8-83.4)\end{array}$ & n.s. & n.s. & & n.s. & n.s. & n.s. \\
\hline \multirow[t]{2}{*}{$\lg E(U I / m L)$} & Success & $\begin{array}{l}462.2 \pm 894.1 \\
180.0(78.0-393.0)\end{array}$ & $\begin{array}{l}546.8 \pm 515.9 \\
346.0(210.0-632.0)\end{array}$ & $\begin{array}{l}398.0 \pm 510.6 \\
217.0(92.0-412.0)\end{array}$ & n.s. & n.s. & n.s. & 0.0113 & n.s. & 0.0003 \\
\hline & Failure & $\begin{array}{l}322.4 \pm 243.7 \\
304.0(148.0-354.0)\end{array}$ & $\begin{array}{l}710.5 \pm 354.9 \\
780.0(372.0-965.0)\end{array}$ & $\begin{array}{l}320.6 \pm 171.2 \\
309.0(162.0-494.0)\end{array}$ & n.s. & n.s. & & 0.0010 & n.s. & 0.0039 \\
\hline \multirow{2}{*}{$\begin{array}{l}\text { Absolute } \\
\text { serum eosinophils } \\
\left(10^{9} / \mathrm{L}\right)\end{array}$} & Success & & $\begin{array}{l}378.8 \pm 361.6 \\
300.0(100.0-400.0)\end{array}$ & $\begin{array}{l}456.2 \pm 562.5 \\
300.0(100.0-600.0)\end{array}$ & - & n.s. & n.s. & - & - & n.s. \\
\hline & Failure & & $\begin{array}{l}395.5 \pm 226.3 \\
400.0(200.0-600.0)\end{array}$ & $\begin{array}{l}585.7 \pm 333.8 \\
500.0(400.0-600.0)\end{array}$ & - & n.s. & & - & - & 0.0156 \\
\hline
\end{tabular}

Each cell shows the mean \pm SD and the median (p25-p75) of the clinical variable in each group according to success/failure of the suspension, for each study visit.

* $p$ Values of the statistically significant differences observed between the success and failure groups of the suspension for the variable at the indicated visit.

$t p$ Values of the statistically significant differences observed for the variable at the indicated visits, compared in the success or failure group of the suspension.

ACT, Asthma Control Test; GETE, Global Evaluation of Therapeutic Efficacy; n.s., no statistically significant difference; VC, visit of cessation.

At V48, 61\% of patients maintained control of asthma (figure 1).

To date this is the largest publication of persistency of efficacy after cessation of omalizumab treatment in 'real life'. Loss of asthma control affected nearly $40 \%$ of patients after 4 years and in most patients within 6-12 months. A rapid decrease of IgE as a predictor of relapse has to be confirmed.

Despite the obvious limitations of an open survey, the results of our real life study suggest that the antiasthmatic effects of 6 years of omalizumab therapy may persist for a long period of time after discontinuation of the treatment.

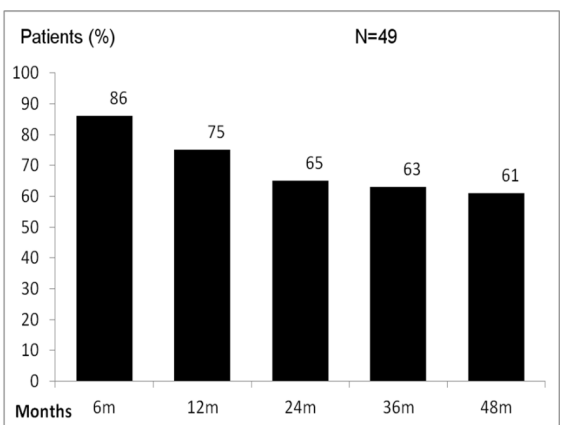

Figure 1 Number of asthmatics (\%) who remained controlled over the 4-year follow-up.
Maria del Carmen Vennera, ${ }^{1,2}$ Carlos Sabadell, ${ }^{3}$ Cesar Picado, ${ }^{1,2}$ on behalf of The Spanish Omalizumab Registry

'Department of Pneumology and Respiratory Allergy, Hospital Clinic, IDIBAPS, Universitat de Barcelona, Barcelona, Spain

${ }^{2}$ Centro de Investigaciones Biomédicas en Red de Enfermedades Respiratorias (CIBERES), Barcelona, Spain

${ }^{3}$ Department of Pneumology, Hospital de Figueres, Figueres, Catalunya, Spain

Correspondence to Dr Maria del Carmen Vennera, Department of Pneumology and Respiratory Allergy, Hospital Clinic, Barcelona 08036, Spain;

mvennera@hotmail.com

Acknowledgements We thank to Dr R Muñoz and Dr E Arismendi for their contribution with their comments to the conclusion of the paper, and also to Dr J Bartra for his continuous stimulus to our work.

Collaborators The Spanish Omalizumab Registry: M J Alvarez Puebla, R Irigaray, E Martínez-Moragón, C Pellicer, C Martínez, X Muñoz, C Cañete, L Marquès, N Marina, S Pascual.

Contributors MCV and CP designed the study. MCV and CS collected data from the Spanish Omalizumab Registry. MCV and CP drafted the manuscript. MCV, CS and $\mathrm{CP}$ contributed to interpretation of the results. All authors read and approved the final manuscript.

Funding This study was supported by a grant from the Spanish Society of Pneumology and Thoracic Surgery (SEPAR).

Competing interests None declared.

Patient consent Obtained.
Ethics approval The study was approved by the Ethics Committee of Clinic Hospital, University of Barcelona.

Provenance and peer review Not commissioned; externally peer reviewed.

(C) Article author(s) (or their employer(s) unless otherwise stated in the text of the article) 2018. All rights reserved. No commercial use is permitted unless otherwise expressly granted.

- Additional material is published online only. To view please visit the journal online (http://dx.doi.org/ 10.1136/thoraxjnl-2017-210017).

Check for updates

To cite Vennera MdC, Sabadell C, Picado C, et al. Thorax 2018:73:782-784.

Received 18 January 2017

Revised 6 October 2017

Accepted 9 October 2017

Published Online First 27 October 2017

Thorax 2018:73:782-784.

doi:10.1136/thoraxjnl-2017-210017

\section{REFERENCES}

1 Humbert M, Busse W, Hanania NA, et al. Omalizumab in asthma: an update on recent developments. J Allergy Clin Immunol Pract 2014;2:525-36.

2 Lowe PJ, Renard D. Omalizumab decreases IgE production in patients with allergic (IgE-mediated) asthma; PKPD analysis of a biomarker, total $\operatorname{lgE}$. Br J Clin Pharmacol 2011;72:306-20. 
3 Ledford D, Busse W, Trzaskoma B, et al. A randomized multicenter study evaluating Xolair persistence of response after long-term therapy. J Allergy Clin Immunol 2017;140: S0091-6749.

4 Vennera MC, Pérez De Llano L, Bardagi S, et al. Omalizumab therapy in severe asthma: experience from the Spanish registry--some new approaches. J Asthma 2012;49:416-22

5 Nathan RA, Sorkness CA, Kosinski M, et al.

Development of the asthma control test: a survey

for assessing asthma control. J Allergy Clin Immunol

2004;113:59-65.
6 Price D. The use of omalizumab in asthma. Prim Care Respir J 2008;17:62-72. 